\title{
ROLE OF VITAMIN D AND RISK OF PROSTATE CANCER
}

\section{Biochemistry}

Milind N Dudhane

Associate professor, Biochemistry Department, Ananta institute of medical sciences and research centre, Rajsamand, Rajasthan, India

Umesh Pareek*

Assistant professor, Biochemistry Department, Ananta institute of medical sciences and research centre, Rajsamand, Rajasthan, India *Correspondnig Author

\section{ABSTRACT}

Background: Vitamin D is a secosteroid hormone and well-known for its classical actions in the maintenance of calcium uptake and bone metabolism. Recently, numerous in vitro experiments demonstrated that 1,25-(OH)2D3, the active form of vitamin D, inhibited the growth and differentiation of human prostate cancer cells.

Aim: To estimate vitamin D level in prostate cancer patients along with increasing risk.

Material \& Methods : 100 samples along with control were analysed by cobas e-411 for Vitamin D and PSA.

Results: we have found Higher risk of prostate cancer who having low vitamin D.

Conclusion: it's time to aware people for supplementation of Vitamin D, so we can prevent for the same.

\section{KEYWORDS}

Vitamin D, Prostate cancer, PSA, hypovitaminosis

\section{INTRODUCTION:}

Deficiency of vitamin D or hypovitaminosis D is widespread irrespective of age, gender, race and geography and has emerged as an important area of research Vitamin D deficiency is prevalent worldwide. This deficiency has many consequences which are still being explored, apart from the well-known skeletal complications. With the consequences of Vitamin D deficiency, namely, autoimmune diseases, cardiovascular diseases, cancer, and tuberculosis being explored. [1]. Vitamin $\mathrm{D}_{3}$ deficiency continues to be an unrecognized epidemic in many populations around the world. Vitamin D is important for the absorption of calcium, and bone formation and maintenance [2] . The incidence of prostate cancer differs between countries due to coverage of prostate-specific antigen (PSA) screening [3]. patients with advanced-stage or metastatic cancer will ultimately progress to castration-resistant prostate cancer [4]. The mechanisms by which prostate cancer progresses to castration-resistant prostate cancer have been studied extensively [5]. Increasing evidence demonstrates that inflammation plays important roles in the pathogenesis of progression to castration-resistant prostate cancer [6]. A double-blinded clinical study found that vitamin D supplementation reduced prostate specific antigen (PSA) level and enhanced survival rate in patients with prostate cancer [7]

On the other hand, vitamin $\mathrm{D}$ receptor (VDR) polymorphisms were associated with the incidence of prostate cancer [7, 8]. Several epidemiological reports showed that men with vitamin D deficiency had a higher risk of prostate cancer compared to men with vitamin D sufficiency $[9,10]$. Nevertheless, the mechanisms through which vitamin D deficiency elevates the risk of prostate cancer remain unclear. The present study aimed to investigate whether there was an association among prostate cancer, vitamin D status in a hospitalbased case-control study.

\section{MATERIALS AND METHODS}

A case control study done in Ananta institute of medical sciences and research centre, Rajsamand. During June 2016- November 2016. In the present study, total 50 newly diagnosed patients with prostate cancer were recruited as cases. Prostate cancer was confirmed by histopathology. 50 Controls were recruited from men undergoing physical examination. Vitamin D and PSA done by chemiluminescence immunoassay methodology. method on Cobas e-411 and chemistry (CRP) ,FBG, creatinine, uric acid, T.G., Total Cholesterol by Cobas Intigra $400^{+}$. Serum samples of all cases and controls were collected at same season and stored at $-20^{\circ} \mathrm{C}$.

\section{RESULTS}

Biochemical characteristics were analyzed as shown in Table 1, no significant difference in $\mathrm{Cr}$, UA, TG, TCH, fasting blood glucose was observed between cases and controls. As expected, serum T-PSA was significantly increased in patients with prostate cancer as compared with control subjects (Table 2 ).

Serum 25(OH)D concentration was analyzed in all subjects. As shown in Figure 1A, serum $25(\mathrm{OH}) \mathrm{D}$ in patients with prostate cancer was significantly lower than in controls.

Table 1

\begin{tabular}{|l|l|l|l|}
\hline Parameters & Case $(\mathbf{5 0})$ & Control $(\mathbf{n}=\mathbf{5 0})$ & P- value \\
\hline FBG & $70 \pm 1.2$ & $69.12 \pm .32$ & $0.81 \mathrm{NS}$ \\
\hline Creatinine & $0.87 \pm .2$ & $0.96 \pm .31$ & $0.734 \mathrm{NS}$ \\
\hline Uric acid & $3.30 \pm 1.1$ & $3.5 \pm 1.28$ & $0.086 \mathrm{NS}$ \\
\hline Triglyceride & $125.25 \pm .25$ & $128.35 \pm 3.25$ & $0.45 \mathrm{NS}$ \\
\hline Total cholesterol & $155.23 \pm 2.3$ & $152.52 \pm 2.35$ & $0.93 \mathrm{NS}$ \\
\hline
\end{tabular}

No significant change

Table- 2

\begin{tabular}{|l|l|l|l|}
\hline Parameters & case $(\mathbf{n}=\mathbf{5 0})$ & Control $(\mathbf{n}=\mathbf{5 0})$ & P- value \\
\hline CRP & $65.01 \pm 2.41$ & $3.01 \pm 0.24$ & $<0.0001^{*}$ \\
\hline Vitamin D & $1.08 \pm .56$ & $8.10 \pm 2.16$ & $<0.0001^{*}$ \\
\hline PSA & $3.70 \pm 2.36$ & $15.12 \pm 1.25$ & $<0.001^{*}$ \\
\hline
\end{tabular}

*Significant change

\section{DISCUSSION}

The present study analyzed the association among prostate cancer, vitamin D status. Our results showed that serum 25-(OH) D was reduced in patients with prostate cancer. By contrast, serum CRP, a marker of systemic inflammation, was elevated in patients with prostate cancer. These results provide evidence for the first time that low vitamin D status is associated with inflammation in patients with prostate cancer.

Chronic inflammation promotes metastases and progression to castration-resistant prostate cancer [11, 12]. CRP could predict tumor aggressiveness and potential treatment efficacy in patients with prostate cancer [13]. According to an early report, CRP is an independent prognostic factor for overall survival of patients with castration-resistant prostate cancer treated with docetaxel [14]. A recent study showed that elevated CRP level was associated with poor prognosis in prostate cancer patients treated with radiotherapy [15] Our results showed that serum $25-(\mathrm{OH}) \mathrm{D}$ level was lower in patients with severe prostate cancer than in patients with mild and moderate prostate cancer. By contrast, serum CRP was higher in patients with prostate. These results suggest that low vitamin D status is associated with inflammation and the progression of prostate cancer.

Increasing evidence indicates that vitamin $\mathrm{D}$ has an anti-inflammatory activity [16]. These results suggest that inflammation may be a key mediator for prostate cancer progression in patients with low vitamin D status. 
The present study has several limitations. First, the present study did not observe whether vitamin D deficiency and inflammation promotes metastasis and progression of prostate cancer. Thus, additional study is required to investigate whether prostatic inflammation promotes prostate cancer in patients with low vitamin $\mathrm{D}$ status.

In summary, the present study investigated the association among prostate cancer, vitamin D status and inflammation. Our results showed that serum 25-(OH) D was decreased in patients with prostate cancer. By contrast, serum CRP was increased in patients with prostate cancer.

\section{REFERENCES}

Attard G, Parker C, Eeles RA, Schröder F, Tomlins SA, Tannock I, Drake CG, de Bono JS. Prostate cancer. Lancet. 2016;387:70-82. doi: 10.1016/S0140-6736(14)61947-4

2. Sharma N, Mangukiya K, Mali KL, Pareek UK and Sharma AK: Comparative Study of the Status of Vitamin D3 in Young Office Working Women and Housewives in Udaipur, Rajasthan. Int J Pharm Sci Res 2015; 6(5): 2197-00.doi: 10.13040/IJPSR.09758232.6(5).2197-00

3. Hayes JH, Barry MJ. Screening for prostate cancer with the prostate-specific antigen test: a review of current evidence. JAMA. 2014; 311:1143-9. doi: 10.1001/jama.2014.2085.

4. Hu MB, Bai PD, Wu YS, Zhang LM, Xu H, Na R, Jiang HW, Ding Q. Higher body mass index increases the risk for biopsy-mediated detection of prostate cancer in Chinese men. PLoS One. 2015; 10:e 0124668. doi: 10.1371/journal. pone.0124668.

5. Wang M, Hu RY, Wu HB, Pan J, Gong WW, Guo LH, Zhong JM, Fei FR, Yu M. Cancer risk among patients with type 2 diabetes mellitus: a population-based prospective study in China. Sci Rep. 2015; 5:11503 doi: 10.1038/srep11503.

6. Ferraldeschi R, Welti J, Luo J, Attard G, de Bono JS. Targeting the androgen receptor pathway in castration-resistant prostate cancer: progresses and prospects. Oncogene. 2015; 34:1745-57. doi: 10.1038/onc.2014.115.

7. Fallowfield L, Payne H, Jenkins V. Patient-reported outcomes in metastatic castrationresistant prostate cancer. Nat Rev Clin Oncol. 2016; 13:643-50. doi: 10.1038/ nrclinonc.2016.100.

8. Wadosky KM, Koochekpour S. Molecular mechanisms underlying resistance to androgen deprivation therapy in prostate cancer. Oncotarget. 2016; 7:64447-70. doi: 10.18632/oncotarget.10901.

Gueron G, De Siervi A, Vazquez E. Advanced prostate cancer: reinforcing the strings between inflammation and the metastatic behavior. Prostate Cancer Prostatic Dis. 2012; 15:213-21. doi: $10.1038 /$ pcan.2011.64.

10. Elder CJ, Bishop NJ. Rickets. Lancet. 2014; 383:1665-76. doi: 10.1016/S01406736(13)61650-5.

11. Munns CF, Shaw N, Kiely M, Specker BL, Thacher TD, Ozono K, Michigami T, Tiosano D, Mughal MZ, Mäkitie O, Ramos-Abad L, Ward L, DiMeglio LA, et al. Global Consensus Recommendations on Prevention and Management of Nutritional Rickets. J Clin Endocrinol Metab. 2016; 101:394-415. doi: 10.1210/jc.2015-2175.

12. Bernichtein S, Pigat N, Barry Delongchamps N, Boutillon F, Verkarre V, Camparo P, Reyes-Gomez E, Méjean A, Oudard SM, Lepicard EM, Viltard M, Souberbielle JC, Friedlander G, et al. Vitamin D3 prevents calcium-induced progression of early-stage prostate tumors by counteracting TRPC6 and calcium sensing receptor upregulation. Cancer Res. 2017; 77:355-65. doi: 10.1158/0008-5472.CAN-16-0687.

13. Luo W, Yu WD, Ma Y, Chernov M, Trump DL, Johnson CS. Inhibition of protein kinase CK2 reduces Cyp24a1 expression and enhances 1,25-dihydroxyvitamin D(3) antitumor activity in human prostate cancer cells. Cancer Res. 2013;73:2289-97. doi: 10.1158/0008-5472. CAN-12-4119.

14. Koike $H$, Morikawa $Y$, Sekine $Y$, Matsui $H$, Shibata $Y$, Suzuki $K$. Survivin is associated with cell proliferation and has a role in 1a,25-dihydroxyvitamin D3 induced cell growth inhibition in prostate cancer. J Urol. 2011; 185:1497-503. doi: 10.1016/j.juro.2010.12.005. 